\title{
SSR markers in revealing extent of genetic diversity and phylogenetic relationships among chickpea core collection accessions for Western Himalayas
}

Reyazul Rouf Mir ( $\square$ imrouf2006@gmail.com)

SKUAST Kashmir: Sher-E-Kashmir University of Agricultural Sciences and Technology Kashmir https://orcid.org/0000-0002-3196-211X

ASMA Hamid Mir

SKUAST Kashmir: Sher-E-Kashmir University of Agricultural Sciences and Technology Kashmir

MOHD ASHRAF BHAT

SKUAST Kashmir: Sher-E-Kashmir University of Agricultural Sciences and Technology Kashmir

Humaira Fayaz

University of Kashmir

Aijaz A Wani

University of Kashmir

Sher A Dar

SKUAST Kashmir: Sher-E-Kashmir University of Agricultural Sciences and Technology Kashmir

Showkat Maqbool

SKUAST Kashmir: Sher-E-Kashmir University of Agricultural Sciences and Technology Kashmir

Mohammad Yasin

RVSKVV: Rajmata Vijayaraje Scindia Krishi Vishwa Vidyalaya

Javid lqbal Mir

CITH: Central Institute of Temperate Horticulture

\section{Mohd Anwar Khan}

SKUAST Kashmir: Sher-E-Kashmir University of Agricultural Sciences and Technology Kashmir

Parvaze A Sofi

SKUAST Kashmir: Sher-E-Kashmir University of Agricultural Sciences and Technology Kashmir

Ahmed H El-Sappah

Yibin University

Mahendar Thudi

ICRISAT: International Crops Research Institute for the Semi-Arid Tropics

\section{Rajeev K Varshney}

Murdoch University 
Keywords: Chickpea, Core collection, Genetic diversity, Microsatellites, Cluster analysis

Posted Date: February 28th, 2022

DOI: https://doi.org/10.21203/rs.3.rs-1354460/v1

License: (c) (1) This work is licensed under a Creative Commons Attribution 4.0 International License. Read Full License 


\section{Introduction}

Chickpea (Cicer arietinum L.) remains as the second most valued cool-season legume crop in the world and becomes increasingly important with climate change [1] offering a cheap source of dietary protein (23\% in dry seed) and provides nutritional and income security in countries like India, Pakistan, and Bangladesh among many other developing countries [2]. It contributes 14.78 million tons to global food production from 14.56 million hectares area across the world with average productivity of 0.96 tons per hectare [3]. In India, chickpea represents national pulse acreage and production of $35 \%$ and $46 \%$, respectively and India serves as the largest chickpea producer (69\%), consumer, and importer globally [4]. The genome sequence of both Kabuli [5] and Desi type [6], whose advanced version was later published by [49] are available thus making chickpea a candidate crop for legume genetic and genomic research.

The genetic variability for the traits of economic importance and the relationship between the cultivated and its wild relatives are of paramount importance for advanced chickpea programs. Domestication, modern plant breeding, and agricultural systems have narrowed the genetic base of cultivated chickpea. This has promoted the need for new sources of variation arising within the germplasm that might be useful in plant breeding programs [5]. However, the large size of germplasm collections, and its inadequate data/information, have resulted in low use $(<1 \%)$ of germplasm further narrowing the genetic base in many crops [7]. India is known as secondary center for its largest diversity in cultivated chickpea [24]. Despite the availability of a diverse and large number of chickpea germplasm collection at the Gene banks like the National Bureau of Plant Genetic Resources (NBPGR), and International Crop Research Institute of Semi-arid Tropics (ICRISAT), a very small proportion has been used in crop improvement/breeding programs mainly because the resources available for evaluation of such large collection is quite limited. The core approach which represents the mini crop collections captures most of the available genetic diversity in the whole germplasm collection, is an efficacious methodology to advance crop improvement programs. Such core sets are costeffective, easy to maintain by individual breeders, and help in the appropriate assessment of genetic diversity, population structure, association analysis and targeted gene mining. Many national programs around the world are actively involved in the utilization of mini cores of crops like chickpea, pigeonpea, groundnut, foxtail millet sorghum, pearl millet, and finger millet, which have led to new and diverse sources of variation for, qualitative and quantitative (biotic/abiotic stress resistance) traits in various crops.

The molecular characterization of the core collection will further enhance its use in genomics for crop improvement programs. Molecular markers can explore the genetic variation in plants and are useful in detecting the duplicates among the core collection and thereby help in designing efficient strategies for optimal sampling from the existing variation. The utility of DNA-based markers for unbiased estimation of molecular diversity and establishing precise phylogenetic relationships among species as compared to morphological, cytological and biochemical markers has been well understood. A variety of molecular markers have been developed in different crop plants and have been used for the study of genetic diversity, population structural analysis and gene discovery programs [51-55]. In chickpea, diverse molecular markers including Amplified fragment length polymorphism (AFLPs) [8], Sequence tagged microsatellite site (STMS) [9], Random amplified polymorphic DNA (RAPDs) [11], Inter simple sequence 
repeat (ISSRs) [12], and SSRs [13-16] have been used for genetic diversity analysis. The desirable genetic attributes (co-dominant inheritance, reproducibility, high degree of polymorphism, bi-/multi-allelic nature, and abundant genomic distribution) of sequence-based robust microsatellite/SSR markers have encouraged their use for many applications of chickpea genetics, genomics, and breeding including cultivar identification, allele mining, genetic mapping, association studies, genetic diversity analysis, population structure studies, and establishing phylogenetic relationships [50, 32]. Large numbers of SSR markers have been identified, characterized, and utilized extensively to identify genetically diverse germplasm with traits of interest for use in chickpea breeding programs [14, 17]. For example, the draft genome sequence of chickpea has led to the identification of over 48,000 SSRs for use as genetic markers [5].

Our recently published information of intensive screening and genetic evaluation of the composite set of 384 chickpea germplasm led to the identification of chickpea core collection, which would enhance the utilization of chickpea genetic resources in crop improvement programs [10]. The present investigation was aimed to further evaluate the level of genetic diversity and allelic richness in the above selected chickpea core set of 192 accessions, using a larger number of thirty-three genome-wide SSR markers. The results derived from this study could be used for more efficient utilization of the entire collection. The microsatellite markers used in the present study were also tested for their ability to detect the extent of genetic diversity by using polymorphism information content values.

\section{Methods}

Germplasm collection

Experimental material for the study comprised of a core set of 192 chickpea accessions, consisting of landraces, elite cultivars, advanced breeding lines, and wild species from the primary, secondary, and tertiary gene pools. These lines include annual cultivated 178 Cicer arietinum lines from the three seed types (kabuli, desi, and intermediate peashaped) and the fifteen (14) wild relatives belonging to Cicer reticulatum Ladiz. (8), Cicer echinospermum P. H. Davis (5), and a perennial Cicer microphyllum Benth (1) species. The seed material of accessions from primary and secondary gene pools has been collected from different hot spots in Turkey under USAID project "Chickpea Innovation Lab"', and the same has been procured by us from ICRISAT, Hyderabad, India. And tertiary gene pool has been collected from its wild natural habitat in Leh/Ladakh region of state Jammu and Kashmir, India. The seed material of cultivated chickpea has been attained from various ethnic/ global institutes. (Supplementary Table EMS_1). Details of some of the accessions like their cold tolerance/ nutrient density are available elsewhere [17, 18]. The genotypes were grown at Research Station of Sher-e-Kashmir University of Agricultural Science and Technology, Kashmir (SKUAST-K), Jammu and Kashmir, India. The passport data of the species is presented in Table 1.

Table 1 Some passport information on Cicer accessions used in the present study.

\begin{tabular}{|l|l|l|l|l|l|l|l|l|}
\hline $\begin{array}{l}\text { S. } \\
\text { No. }\end{array}$ & Species & $\begin{array}{l}\text { Biolo } \\
\text { gical } \\
\text { status }\end{array}$ & $\begin{array}{l}\text { Breeding } \\
\text { cycle }\end{array}$ & $\begin{array}{l}\text { Gen } \\
\mathrm{e} \\
\text { pool }\end{array}$ & Inbreeding & Origin & $\begin{array}{l}\text { Geographical } \\
\text { Distribution }\end{array}$ & $\begin{array}{l}\text { Latitud } \\
\text { e range } \\
\left({ }^{\circ} \mathrm{N}\right)\end{array}$ \\
\hline
\end{tabular}




\begin{tabular}{|l|l|l|l|l|l|l|l|l|}
\hline 1 & C. arietinum & $\begin{array}{l}\text { Cultiv } \\
\text { ated }\end{array}$ & Annual & $1^{\circ}$ & Inbreeder & India & $\begin{array}{l}\text { North, Central and } \\
\text { Peninsular India }\end{array}$ & $\begin{array}{l}8.7- \\
40.0\end{array}$ \\
\hline 2 & $\begin{array}{l}\text { C. reticulatum } \\
\text { Ladizinsky }\end{array}$ & Wild & Annual & $1^{\circ}$ & Inbreeder & Turkey & $\begin{array}{l}\text { East Turkey (South } \\
\text { East Anatolia) }\end{array}$ & $\begin{array}{l}37.3- \\
38.1\end{array}$ \\
\hline 3 & $\begin{array}{l}\text { C. } \\
\text { echinospermum } \\
\text { P.H.Davis }\end{array}$ & Wild & Annual & $2^{\circ}$ & Inbreeder & $\begin{array}{l}\text { Turkey } \\
\text { and Syria }\end{array}$ & $\begin{array}{l}\text { East Turkey (East } \\
\text { Anatolia), North } \\
\text { Iraq }\end{array}$ & $\begin{array}{l}36.9- \\
37.9\end{array}$ \\
\hline 4 & $\begin{array}{l}\text { C. } \begin{array}{l}\text { microphyllum } \\
\text { Benth. }\end{array} \\
\text { Benth }\end{array}$ & Wild & Perennial & $3^{\circ}$ & Outbreeder & $\begin{array}{l}\text { India and } \\
\text { Turkey }\end{array}$ & $\begin{array}{l}\text { North India (hot } \\
\text { spots of Leh/ } \\
\text { Ladakh) }\end{array}$ & $\begin{array}{l}34.1- \\
35.0\end{array}$ \\
\hline
\end{tabular}

\section{DNA Isolation}

Three weeks after planting, approximate leaf samples were collected from five plants of each accession, lyophilized, and grounded to fine powder to extract the total genomic DNA following the cetyl triethyl ammonium bromide (CTAB) technique [19] with slight modifications. The extracted DNA was purified by treating with RNase to remove the RNA contamination. The purified DNA was quantified and its quality was accessed using NanoDrop Spectrometer and based on its result, 85 accessions were selected to validate the results on $0.8 \%$ agarose gel (Fig. 1). Based on the intensity of the bands, working DNA was diluted for marker genotyping.

\section{SSR Markers}

A total of 33 SSR markers spanning the entire chickpea genome, one marker at least covering each arm of the 8 linkage groups, were selected to characterize the set of 192 core chickpea accessions (Fig. 2). These SSR primer pairs were selected from the composite collections of the chickpea database (CicArMiSatDB: the chickpea microsatellite database (https:// cegresources.icrisat.org/CicArMiSatDB/) developed by ICRISAT. The database contains SSRs which are reported by [5]. The details of SSR primer-pairs are provided in Supplementary Table EMS_2.

\section{PCR Amplification}

To study polymorphism in the chickpea core collection, PCR amplification was carried out in a Universal Gradient Thermal Cycler with 96 wells using a $20-\mu \mathrm{L}$ reaction mixture: $2 \mu \mathrm{L}$ of template DNA ( $25 \mathrm{ng} / \mu \mathrm{L}), 10 \mathrm{x}$ PCR buffer (1.8 mM, MgCl2, $10 \mathrm{mM}$ Tris-HCl, $50 \mathrm{mM} \mathrm{KCl),} 2.5 \mathrm{mM}$ dNTPs (Molecular Biology for Life Science, Fermentas, Lithuania, USA), $5 \mu \mathrm{M}$ each of forward and reverse primer and $5 \mathrm{U}$ of Taq DNA polymerase (Sigma Aldrich USA. The thermal cycler (Peqlab) was programmed as follows: initial denaturation for $5 \mathrm{~min}$ at $94^{\circ} \mathrm{C}$ followed by 40 cycles of denaturation for 30 seconds (s) at $94{ }^{\circ} \mathrm{C}$, annealing at temperature specific for each primer pair for $30 \mathrm{~s}$ and extension at $72{ }^{\circ} \mathrm{C}$ for $30 \mathrm{~s}$. The final extension was allowed for $10 \mathrm{~min}$ at $72{ }^{\circ} \mathrm{C}$ and storage at $4{ }^{\circ} \mathrm{C}$ until further use. The resulting PCR products were run on 10\% Poly-acrylamide Gel Electrophoresis (PAGE) using a Dual Gel Vertical Electrophoresis System (Peqlab) and silver stained for manual visualization of bands on gel documentation system.

Data analysis 
The allelic data scored, was used to analyze genetic diversity parameters using GenALex v.6.5b3 [20]. The overall diversity, number of alleles ( $\mathrm{Na}$ ), the effective number of alleles $(\mathrm{Ne})$, number of private alleles, and gene diversity measured as expected heterozygosity (He), was measured along with other parameters. Total genetic variation was partitioned among and within population subgroups, was computed by analysis of molecular variance (AMOVA). Allellic frequency was calculated using Polymorphism Information Content (PIC) values which indicates the ability of markers to differentiate the genotypes was calculated as $1-\Sigma(\mathrm{fij})^{2}$ where fij is the frequency of the jth allele for ith locus summed across all alleles for the locus [21]. For the calculation of the pairwise genetic distances, DARwin version 5.0 was used [22]. The dissimilarity matrix obtained was subjected to cluster analysis, using the Unweighted Pair Group Method with Arithmetic Average (UPGMA) based hierarchical clustering for the construction dendrograms.

\section{Results}

A set of 33 primer pairs physically mapped across the chickpea genome showed reproducible amplification and 100\% polymorphism through the core collection of 192 cultivated and wild Cicer accessions using the polyacrylamide gelbased assay. The visual observation of polyacrylamide gel pictures is indicated in Fig. 3. The SSR markers used in this study were found informative enough to explain genetic variation among core chickpea accessions.

\section{Allelic and Gene diversity}

A total of 323 alleles (Na) were identified at 76 marker loci generated by 33 SSR markers giving an average of 4.25 alleles per marker locus. The microsatellite marker locus CaGM06707A (mapped on LG2) was the most variable with maximum (eight) 8 alleles and microsatellite marker locus CaGM06221B was least variable with only (two) 2 alleles. The total number of effective alleles (Ne) was 263.96 with an average of 3.47 alleles/locus. The number of effective alleles was lower than the total number of alleles, showing that only a few alleles contributed to the variation. The average number of private alleles i.e, the number of alleles unique to single population was 4.25.

Gene diversity (expected heterozygosity; $\mathrm{He}$ ) was variable across loci reflecting the different number and frequencies of the alleles found. The average gene diversity of the core collection was found moderate (0.68), showing that two randomly chosen genes will carry different alleles roughly half of the time. The lowest $\mathrm{He}(0.46)$ was recorded for SSR marker locus CaGM12686E and the highest $\mathrm{He}$ (0.86) for SSR marker locus CaGM06707A For each population, the observed heterozygosities (Ho) were less than the expected heterozygosities (He) (Table 2, Fig. 4).

Table 2 Comparison of diversity estimates in the whole population and two sub-populations (cultivated and wild) of core chickpea accessions.

\begin{tabular}{|c|c|c|c|}
\hline & Whole population & $\begin{array}{c}\text { Sub-population } \\
\text { (Cultivated) }\end{array}$ & $\begin{array}{c}\text { Sub-population } \\
\text { (Wild) }\end{array}$ \\
\hline Diversity parameters & \multicolumn{3}{|c|}{ Mean } \\
\hline $\mathbf{N}$ & 191.605 & 177.605 & 13.052 \\
\hline $\mathbf{N a}$ & 4.250 & 4.250 & 3.289 \\
\hline
\end{tabular}




\begin{tabular}{|c|c|c|c|}
\hline Na Freq. >= 5\% & 4.026 & 4.026 & 3.263 \\
\hline $\mathbf{N e}$ & 3.473 & 3.468 & 2.602 \\
\hline Number of private alleles & 4.250 & 0.961 & 0.000 \\
\hline He & 0.687 & 0.686 & 0.572 \\
\hline UHe & 0.688 & 0.688 & 0.592 \\
\hline
\end{tabular}

$* \mathrm{~N}=$ sample size; $\mathrm{Na}=$ no. of different alleles; $\mathrm{Na}$ Freq. $>=5 \%=$ number of different alleles with a frequency $>=5 \%$ ); $\mathrm{Ne}=$ no. of effective alleles;

$\mathrm{He}=$ expected heterozygosity; $\mathrm{UHe}=$ unbiased expected heterozygosity.

\section{Polymorphic Information Content (PIC)}

The PIC value provides an idea about the polymorphism detected by the marker system and its suitability for the study of genetic diversity. The higher the PIC value of a locus, the higher the number of alleles detected. During the present study, the PIC value of all the 76 polymorphic SSR marker loci on all 192 chickpea core set varied from 0.73 to 0.98 with an average of 0.89 . Interestingly, all the marker loci were highly informative with the PIC value of $>0.50$. Markers CaGM06707A, CaGM12686E, and CaGM19859B were most informative with high PIC value of 0.98, 0.98, and 0.97, respectively. SSR marker $C a G M 12686 E$ and $C a G M 06221 B$ showed the least PIC value of 0.72 and 0.73 , respectively. (Table 3). The correlation worked out between the PIC value and the number of alleles was significantly positive $(\mathrm{r}=0.67, \mathrm{p}<0.01)$.

Table 3 Profile of 76 SSR marker loci detected during the present study across the core chickpea accessions.

\begin{tabular}{|c|c|c|c|c|c|c|c|}
\hline Marker Locus & $\mathbf{N a}$ & $\mathrm{He}$ & PIC & Marker Locus & $\mathbf{N a}$ & $\mathrm{He}$ & PIC \\
\hline CaGM01708A & 3 & 0.65 & 0.88 & CaGM17047A & 3 & 0.65 & 0.88 \\
\hline CaGM01708B & 6 & 0.77 & 0.95 & CaGM17047B & 5 & 0.78 & 0.95 \\
\hline CaGM01708C & 4 & 0.70 & 0.91 & CaGM18946A & 4 & 0.74 & 0.93 \\
\hline CaGM01843A & 5 & 0.53 & 0.78 & CaGM18946B & 4 & 0.66 & 0.89 \\
\hline CaGM01843B & 3 & 0.58 & 0.83 & CaGM19859A & 4 & 0.66 & 0.89 \\
\hline CaGM02077A & 4 & 0.64 & 0.87 & CaGM19859B & 7 & 0.83 & 0.97 \\
\hline CaGM02077B & 3 & 0.62 & 0.86 & CaGM19859C & 4 & 0.74 & 0.93 \\
\hline CaGM02077C & 4 & 0.70 & 0.91 & CaGM21172A & 4 & 0.72 & 0.92 \\
\hline CaGM05058A & 4 & 0.68 & 0.90 & CaGM21172B & 7 & 0.80 & 0.96 \\
\hline CaGM05058B & 3 & 0.57 & 0.82 & CaGM21237A & 4 & 0.65 & 0.88 \\
\hline CaGM06221A & 4 & 0.68 & 0.90 & CaGM21237B & 3 & 0.65 & 0.88 \\
\hline CaGM06221B & 2 & 0.47 & 0.73 & CaGM21237C & 3 & 0.62 & 0.86 \\
\hline CaGM06707A & 8 & 0.86 & 0.98 & CaGM22088A & 4 & 0.74 & 0.93 \\
\hline CaGM06707B & 5 & 0.77 & 0.95 & CaGM22088B & 6 & 0.77 & 0.95 \\
\hline CaGM06707C & 4 & 0.73 & 0.93 & CaGM2251A & 4 & 0.73 & 0.93 \\
\hline
\end{tabular}




\begin{tabular}{|l|l|l|l|l|l|l|l|} 
CaGM06707D & 3 & 0.65 & 0.88 & CaGM25867A & 5 & 0.73 & 0.93 \\
\hline CaGM07849A & 4 & 0.74 & 0.94 & CaGM25867B & 4 & 0.74 & 0.94 \\
\hline CaGM07849B & 4 & 0.73 & 0.93 & CaGM27129A & 3 & 0.62 & 0.86 \\
\hline CaGM07849C & 5 & 0.78 & 0.95 & CaGM27129B & 4 & 0.66 & 0.89 \\
\hline CaGM08077A & 6 & 0.82 & 0.97 & CaGM30464A & 3 & 0.52 & 0.77 \\
\hline CaGM08077B & 6 & 0.70 & 0.97 & CaGM30464B & 5 & 0.71 & 0.92 \\
\hline CaGM08077C & 5 & 0.59 & 0.91 & CaGM30464C & 4 & 0.69 & 0.90 \\
\hline CaGM08077D & 3 & 0.66 & 0.83 & CaGM31868A & 4 & 0.64 & 0.88 \\
\hline CaGM10213A & 3 & 0.65 & 0.88 & CaGM31868B & 6 & 0.74 & 0.94 \\
\hline CaGM10213B & 4 & 0.74 & 0.94 & CaGM32104A & 3 & 0.58 & 0.83 \\
\hline CaGM10213C & 6 & 0.82 & 0.97 & CaGM32104B & 3 & 0.58 & 0.83 \\
\hline CaGM10922A & 3 & 0.55 & 0.80 & CaGM32104C & 5 & 0.74 & 0.93 \\
\hline CaGM10922B & 3 & 0.61 & 0.85 & CaGM3430A & 3 & 0.65 & 0.88 \\
\hline CaGM10922C & 7 & 0.78 & 0.96 & CaGM37999A & 5 & 0.74 & 0.94 \\
\hline CaGM12686A & 7 & 0.80 & 0.96 & CaGM37999B & 4 & 0.71 & 0.92 \\
\hline CaGM12686B & 3 & 0.54 & 0.79 & CaGM4755A & 3 & 0.66 & 0.89 \\
\hline CaGM12686C & 3 & 0.48 & 0.74 & CaGM6470A & 3 & 0.64 & 0.87 \\
\hline CaGM12686D & 4 & 0.65 & 0.88 & CaGM7233A & 4 & 0.74 & 0.96 \\
\hline CaGM12686E & 4 & 0.46 & 0.72 & CaGM30437A & 6 & 0.78 & 0.96 \\
\hline CaGM16791A & 4 & 0.71 & 0.92 & CaGM29870A & 3 & 0.56 & 0.81 \\
\hline CaGM16791B & 4 & 0.64 & 0.87 & CaGM29870B & 4 & 0.70 & 0.91 \\
\hline CaGM16791C & 4 & 0.70 & 0.91 & CaGM29870C & 4 & 0.66 & 0.89 \\
\hline CaGM16840A & 4 & 0.69 & 0.90 & CaGM27129A & 5 & 0.55 & 0.80 \\
\hline
\end{tabular}

$* \mathrm{Na}=$ Number of different alleles, $\mathrm{He}=$ Expected Heterozygosity; PIC $=$ Polymorphic information content .

\section{Allelic/ Gene diversity across sub-populations (cultivated and wild)}

The allelic/genetic patterns studied across the populations are presented in Table 2. The allelic diversity, when studied within two sub-populations (cultivated v/s wild), revealed a total number of 345 alleles with an average of 4.25 alleles/locus observed in the cultivated sub-population, as against a total number of 201 alleles with an average of 3.28 alleles/locus in wild sub-population. The average number of effective alleles $(\mathrm{Ne})$ was observed to be 3.46 in cultivated chickpea, and that of 2.60 in wild chickpea. The number of alleles with frequency $\geq 5$ percent (Na Freq. $\geq 5 \%$ ), (i.e, measurement taken to alleviate the sampling error associated with the sampling of distinct alleles) was for cultivated and wild sub-populations was 4.02 and 3.26, respectively. The average number of private alleles (alleles unique to a single population) was 0.96 in the cultivated sub-population. However, no private allele was found among the wild sub-population. Since the sample size between the two sub-populations was not equal, the resampling technique was therefore used, to make valid comparisons of diversity, wherein a small sample size i.e, 14 for wilds was drawn 
randomly 3000 times from the 178 cultivated group and average mean alleles were recorded. The mean alleles/locus for the cultivated group based on a sample size of 14 genotypes was found to be 3.65 . The more diversity apparent in cultivated sub-population may be attributed to the presence of private alleles in the group ( $m$ ean private alleles $=0.96$ ), while no private alleles were present in the wild sub-population. Similarly, gene diversity (expected heterozygosity; $\mathrm{He}$ ) was observed to be higher in cultivated sub-population and varied from 0.14 to 0.80 with an average of 0.68 , and from 0.09 to 0.75 with an average of 0.57 in wilds (Fig.4).

\section{Analysis of Molecular Variance (AMOVA) and partitioning genetic diversity}

The results of the analysis carried out among and within the two sub-populations (cultivated and wild) showed that the observed variance was mostly partitioned among individuals $(87 \%)$, whereas 7 percent of the variance was partitioned within individual accessions and the rest 6 percent was among populations (Table 4). The low level of genetic variation among populations is indicative of gene flow between populations. Since the maximum number (8) of the wilds in the present study are from $C$. reticulatum which is the progenitor of cultivated species C. arietinum leading to smooth introgression of genes. The value of pairwise comparisons of population differentiation (Fst) and Gene flow (Nm) among of chickpea sub-populations are indicated in Table 5. There is a moderate amount of genetic differentiation between the groups $\left(\mathrm{F}_{\mathrm{ST}}=0.10\right)$, indicating that the groups are less genetically distinct. The $\mathrm{F}_{\mathrm{IS}}$ and $\mathrm{F}_{\mathrm{IT}}$ values are 0.92 and 0.82 respectively indicating that the chickpea accessions making up the individual groups are inbred lines. Furthermore, the gene flow $(\mathrm{Nm})$ between the groups was observed to be 4.26, suggesting a high level of gene flow (Table 5).

Table 4 Analysis of molecular variance showing distribution of genetic diversity among and within sub-populations of core chickpea accessions.

\begin{tabular}{|l|l|l|l|l|l|}
\hline Source & df & SS & MS & $\begin{array}{l}\text { Estimated } \\
\text { Variance }\end{array}$ & \%ariance \\
\hline Among Populations & 1 & 134.50 & 134.50 & 1.52 & 6 \\
\hline Among Individuals & 190 & 9517.43 & 50.09 & 24.04 & 87 \\
\hline Within Individuals & 192 & 384.00 & 2.000 & 2.00 & 7 \\
\hline Total & 383 & 10035.93 & & 27.57 & 100 \\
\hline
\end{tabular}

$* \mathrm{df}=$ degree of freedom; $\mathrm{SS}=$ sum of squares; $\mathrm{MS}=$ mean sum of squares.

Table 5 Genetic differentiation between the studied sub-populations (cultivated and wild).

\begin{tabular}{|l|l|}
\hline F-Statistics & Value \\
\hline Fst & 0.10 \\
\hline Fis & 0.92 \\
\hline Fit & 0.82 \\
\hline $\mathrm{Nm}$ & 4.26 \\
\hline
\end{tabular}

*Fst= Pairwise genetic differentiation, $\mathrm{Nm}=$ number of effective migrants. 


\section{Cluster analysis}

Cluster analysis based on the dissimilarity index values delineated 192 chickpea accessions into 4 main clusters by employing all the 76 marker loci, the results of which are presented in Fig. 5. The cluster-I contained 25 accessions which were all cultivated species. Cluster-II possessed 29 accessions, which include wilds from the three gene pools (C. reticulatum (3), C. echinospermum (5), and C. microplyllum (1)) and the remaining 20 in the cluster were cultivated C. arietinum. A slight speciation pattern of structure was detected especially in cluster-II, where the wild accessions belonging to three different gene pools were grouped in close vicinity. Cluster-III had a total of 53 accessions wherein all cultivated except 1 wild species (C.reticulatum) were included. Cluster-IV was the largest cluster with 85 accessions which included four $C$. reticulatum species and 81 cultivated species. These results infer that wild $C$. reticulatum belonging to primary gene pool was present with C. arietinum (cultivated) in three out of four clusters, owing to the origin of cultivated C. arietinum from the wild progenitor. Also, among all the four clusters, the cluster II was found to be the most heterogeneous.

\section{Discussion}

An extensive characterization of plant genetic resources and an understanding of the genetic relationships in the germplasm collection is essential for effective conservation, management, and exploitation of genetic resources in varietal improvement programs. Also, the use of wild species provides a wider genetic base in otherwise, less diverse cultivated chickpea and is known as a potential source of resistance genes for various biotic and abiotic stresses [23]. Thus, the investigation of the nature and magnitude of genetic diversity and relatedness within and among the cultivated chickpea and its wild relatives is an obvious necessity to identify new sources of variation in the existing germplasm. A core set of chickpea acts as a working collection having an optimal and convenient size that can be evaluated for all important traits with minimum error rates. Intensive screening and evaluation of the core collections have led to the identification of diverse accessions leading to the advancement of plant breeding and thus paving the way towards booming crop improvement programs. To cite an example, the utility of the chickpea core set (300 accessions) capturing $78.1 \%$ alleles of the composite collection, developed at ICRISAT [25] has been extensively used in breeding as well as germplasm management and improvement. The molecular characterization of the core collection provides information related to unique/rare alleles from cultivated and wild species which could be used to select distinct genotypes for allele mining. Among the variety of molecular markers already developed and used in breeding programs, SSRs are considered markers of choice [26, 27]. Universal distribution and high density in a multitude of genomes along with other merits associated with SSR markers enhance their desirability, especially for germplasm characterization and have been extensively used for identification of variation in chickpea germplasm. Therefore, efforts were made during the present study to carefully select random SSR markers covering all the eight linkage groups of chickpea genome. 
In this study, every SSR primer pair successfully amplified the target DNA in a core set of 192 chickpea accessions. The 33 random markers generated 76 polymorphic loci and were useful for detection of a total of 323 alleles (Na) at all marker loci. The average number of alleles/locus (4.25) found in this study are within the ranges reported by many earlier studies. A relatively higher density was observed in our core collection when compared to our previous study on genetic diversity in a composite set of 384 genotypes using 8 SSR markers which generated a total of 63 (Na) alleles with an average of $3.7 /$ locus, indicating that the chickpea core maximized the diversity available in the entire composite germplasm set. Our observations are fairly comparable with earlier genetic diversity studies on the cultivated and wild Cicer accessions using random microsatellite markers with some deviations. For instance, the use of 478 microsatellites identified a total of 3703 alleles with an average of 4.26 alleles/marker locus in 94 cultivated and wild chickpea accession [28]. Similarly, 38 accessions of Cicer arietinum using 100 SSR markers generated an average of 4.8 amplicons per locus [17]. Likewise, a total of 59 alleles with an average of 4.2 alleles/locus in 60 chickpea accessions were reported using14 SSR markers [15]. Similar results were also observed by [16] where he reported an average of 3.88 alleles/locus in 66 Cicer arietinum accessions. However, the level of diversity detected in the present study was less while comparing it with average number of alleles/locus $(35,17,10.3,7.4,8.61,7.75,10.5)$ detected by $[30-35,13]$. There are also reports where even less diversity than in our case has been reported. For example, 33 microsatellites were used to study genetic diversity in 155 chickpea accessions which resulted in a total of 111 bands with a range of 2-5 alleles/locus and on average 3.364 bands per marker [14]. In another study, using 27 SSR markers a total of 81 alleles with an average of 3.0 alleles per locus were detected in 50 chickpea genotypes [36]. The use of more cultivated chickpea accessions which possess narrow genetic base as reported by various researchers [37- 40] may have led to observance of less diversity in our study. Likewise, higher polymorphic potential among the species/accessions originating from Fertile Crescent (79.5\% polymorphism) in contrast to those from Central AsiaIndia (35.8\%) was also reported by [28]. Since the majority of the germplasm used in the present study is indigenous which may have attributed to the presence of less diversity in our chickpea core collection. The inclusion of more chickpea wild species could produce a higher number of allele count/locus as suggested by [30, 15]. The overall genetic diversity $(\mathrm{He})$ showed relatively moderate value of expected heterozygosity $(\mathrm{He}=0.68)$ which are comparable to previous studies [15, 33, 41-42]. Differences in results for estimated genetic diversity between studies may be attributed to the different number of accessions, different number of loci examined, nature of markers, and perhaps the geographical origin of the accessions used in each study. The inter and intra- specific polymorphism, when studied within two sub-populations (cultivated vs wild), did not differ much from the single population of 192 chickpea accessions, where the average number of alleles per locus for cultivated sub-population was 4.25 , while that for wild was found to be 3.28. These results indicate that the number of accessions could still be reduced to study genetic diversity. The mean private alleles in cultivated was (0.96) and no private alleles in wilds were detected within the two sub-populations. Similar results were shown by [30], where no rare alleles were found in wild accessions. Among the two sub-populations, cultivated chickpea showed more diversity (possessing more number of private alleles and an average number of alleles/locus than wild population, which could be due to very less number of wild accessions involved in our study as compared to the large number of cultivated accessions used. The inclusion of more wild 
accessions particularly from secondary and tertiary gene pools could result in a higher level of diversity since most of the desirable gene complexes are present in them. For instance, a higher degree of polymorphism was detected among the accessions belonging to the secondary gene pool as compared to primary gene pool [28].

The Polymorphic information content (PIC) value, indicated that all the markers used in the present study were informative with a PIC value greater than 0.50 . The average PIC value for the 76 marker loci was 0.89 which suggests that the majority of markers enabled a high level of polymorphism and could be effective to determine the genetic differences among the chickpea accessions studied. Similar to our results the average PIC values of $0.77,0.75,0.75$, 0.72 , were observed by $[13,29,35,43]$, respectively. Comparatively, a high average PIC value of 0.854 has been reported by [30], and [17, 36, 44-45] revealed an average PIC value of $0.53,0.60,0.68$, and 0.43 , respectively which is relatively less than that of the present study.

AMOVA is a method to study population differentiation utilizing molecular markers [46]. To evaluate the extent of population differentiation among/between the sub-populations (cultivated and wild) in the present study, the molecular variance based on 99 permutations was analyzed using 33 random SSR markers. The analysis of the two subpopulations showed that most of the variation was among individuals (87\%), and $7 \%$ of the variation was partitioned within individuals. The relatively higher variation among individuals could be attributed to the differences among genotypes within sub-populations. In agreement with our results, [47] reported higher variance $(61 \%)$ among the populations compared to within (39\%) populations. Similarly, $71 \%$ of the allelic variation was documented among the domesticated and the wild gene pools and the remaining $29 \%$ of the allelic variation was observed within them [48].

To decipher the phylogenetic relationships between accessions and closest and distant genotypes from each other, UPGMA based Hierarchical clustering approach was found best in the present study for interpretation of results. The 33 random SSR markers could cluster chickpea core collection of chickpea accessions into 4 main clusters, and several sub-clusters and sub-sub clusters, whereby the different members within a cluster are assumed to be more closely related to each other than with those members in different clusters. From the present investigation, it was found that accessions of different origins/species were grouped together in different clusters. The $C$. reticulatum accessions fell in 3 clusters out of 4 main clusters. All accessions belonging to C. echinospermum were clustered in a single cluster (cluster II). Another feature of the tree is the relative position of the single C. microphyllum accession (belonging to tertiary gene pool) in close vicinity of $C$. echinospermum accessions (secondary gene pool). This may suggest that both species are closely related to each other (Fig. 5). Similarly, [8] used Nei's pairwise distance calculations and identified clustering of cultivated species Cicer arietinum, Cicer reticulatum and, Cicer echinospermum in the same group. It can be inferred from this study that SSR markers were effective in placing chickpea accessions in appropriate clusters based on relationships at an evolutionary level. The allelic/genetic diversity, PIC values, molecular variation, phylogenetic relationship information generated in this study for the set of 192 chickpea core collection and with the availability of current genomic tools, could have implications for many genotyping applications including allele mining, gene tagging association analysis and QTL mapping targeting different qualitative and quantitative traits of agricultural importance in chickpea. 


\section{Conclusion}

The present study shows the potential use and efficacy of selected polymorphic microsatellite markers used to study genetic diversity among the core chickpea accessions. Our results revealed the existence of considerable genetic diversity, with majority of the variation found among the individuals, and provided information on phylogenetic relationships among the members of different gene pools. The core collection is regarded as the gateway to unravel the diversity estimates. Our results revealed that the core collection exhibited greater diversity than the entire composite chickpea germplasm from which it was derived. This result will have direct application in efficient conservation and sustainable utilization of germplasm. And shall provide greater confidence to the breeding community for assessment of distinctiveness and relationships among the various accessions. The chickpea core collection is expected to ensure effective core deployment, especially for future chickpea varietal identification, conservation, and management, and the development of broad-based/ climate resilient cultivars that should meet the immediate and future breeding challenges.

Author contributions Conceptualization, RRM; MAB; and AHM; data analysis, RRM; methodology, RRM; AHM; and HF writing-original draft, AHM; review and editing, MRR; MAB; AAW; SAD; SM; MY; JIM; AK; PAS; AHE$\mathrm{S}$; MT; and RKV. All authors have read and agreed to the published version of the manuscript.

Acknowledgments The authors are thankful to ICRISAT (Hyderabad), IIPR (Kanpur), NBPGR (New Delhi) for providing the germplasm for the present study. Thanks are also due to Douglas R cook at University of California at Davis (UC Davis), California, USA for providing seed material of some wild relatives through ICRISAT, Hyderabad.

Funding This study was not funded by any funding agency.

Data availability The data analyzed and generated during the current study are available within the article [and/or] its supplementary materials.

\section{Declarations}

Conflict of interest The authors declare that they have no conflict of interest.

Ethical approval This article does not contain any studies/ research with human or animal subjects.

\section{Literature cited:}


1. Mallikarjuna BP, Samineni S, Thudi M, Sajja SB, Khan AW et al (2017) Molecular mapping of flowering time major genes and QTLs in Chickpea (Cicer arietinum L.). Front Plant Sci 8:1140

2. Archak S, Tyagi RK, Harer PN, Mahase LB, Singh, N, Dahiya, OP et al (2016) Characterization of chickpea germplasm conserved in the Indian National Genebank and development of a core set using qualitative and quantitative trait data. Crop J 4(5): 417-424

3. FAOSTAT, Food and Agriculture Organization of the United Nation Statistics for (2017) Online database at https://www.fao.org/faostat/en/\#data

4. Annual Report DPD. 2017-18. Directorate of Pulses Development, Ministry of Agriculture and Farmers Welfare, Government of India, DPD/Pub./TR/29/2017-18

5. Varshney RK, Song C, Saxena RK, Azam S, Yu S, Sharpe AG et al (2013) Draft genome sequence of chickpea (Cicer arietinum) provides a resource for trait improvement. Nat Biotechnol 31(3): 240.

6. Jain M, Misra G, Patel RK, Priya P, Jhanwar S, Khan AW (2013) A draft genome sequence of the pulse crop chickpea (Cicer arietinum L.). The Plant Journal 74: 715-729

7. Upadhyaya HD, Yadav D, Dronavalli N, Gowda CLL, Singh, S (2010) Mini core germplasm collections for infusing genetic diversity in plant breeding programs. Electron. J. Plant Breed 1(4): 1294-1309

8. Nguyen TT, Taylor PWJ, Redden RJ, Ford R (2004) Genetic diversity estimates in Cicer using AFLP analysis. Plant Breed 123(2): 173-179

9. Sethy NK, Shokeen B, Edwards KJ, Bhatia S (2006) Development of microsatellite markers and analysis of intra specific genetic variability in chickpea (Cicer arietinum L.). Theor. Appl. Genet 1(12): 1416-1428

10. Fayaz H, Mir AH, Tyagi S, Wani AA, Jan N, Yasin M, Mir JI, Mondal B, Khan MA, Mir RR (2021) Assessment of molecular genetic diversity of 384 chickpea genotypes and development of core set of 192 genotypes for chickpea improvement programs. Genet. Resour. Crop Evol doi:10.1007/s10722-021-012960

11. Talebi REZA, Fayaz F, Mardi M, Pirsyedi SM, Naji AM (2008) Genetic relationships among chickpea (Cicer arietinum) elite lines based on RAPD and agronomic markers. Int J Agric Biol 10(3): 301-305

12. Jida Z, Alemu A, Mullualem D (2018) Genetic diversity among elite chickpea (Cicer arietinum L.) varieties of Ethiopia based on inter simple sequence repeat markers. Afr. J. Biotechnol 17(34): 1067-1075

13. Sefera T, Abebie B, Gaur PM, Assefa K, Varshney RK (2011) Characterisation and genetic diversity analysis of selected chickpea cultivars of nine countries using simple sequence repeat (SSR) markers. Crop Pasture Sci 62(2): 177-187

14. Keneni G, Bekele E, Imtiaz M, Dagne K, Getu E, Assefa F (2012) Genetic diversity and population structure of Ethiopian chickpea (Cicer arietinum L.) germplasm accessions from different geographical origins as revealed by microsatellite markers. Plant Mol. Biol. Rep 30(3): 654-665

15. Ghaffari P, Talebi R, Keshavarzi F (2014) Genetic diversity and geographical differentiation of Iranian landrace, cultivars, and exotic chickpea lines as revealed by morphological and microsatellite markers. Physiol Mol Biol Plants 20(2): 225-233 
16. Aggarwal H, Choudhary SP, Rana MK, Choudhary R (2018) Assessment or Evaluation of Genetic Diversity among 66 Cultivars of Chickpea (Cicer arietinum L.) of Indian Origin Using SSR Markers. Int. J. Curr. Microbiol. Appl. Sci 7(2): 523-533

17. Choudhary P, Khanna SM, Jain, PK (2012) Genetic structure and diversity analysis of the primary gene pool of chickpea using SSR markers. Genet. Mol. Res 11(2): 891-905

18. Mir AH, Bhat MA, Dar SA, Sofi PA, Bhat NA, Mir RR (2021) Assessment of cold tolerance in chickpea (Cicer spp.) grown under cold/freezing weather conditions of North-Western Himalayas of Jammu and Kashmir, India. Physiol Mol Biol Plants https://doi.org/10.1007/s12298-021- 00997-1

19. Fayaz H, Rather IA, Wani AA, Tyagi S, Pandey R, Mir RR (2019) Characterization of chickpea gene pools for nutrient concentrations under agro-climatic conditions of North- Western Himalayas. Plant Genet Resour $17: 464-467$

20. Saghai-Maroof MA, Soliman, KM, Jorgensen, RA, Allard, RW (1984) Ribosomal DNA spacer length polymorphism in barley: Mendelian inheritance, chromosomal location and population dynamic. Proceedings of the National Academy of Sciences United States of America 81: 8014-19

21. Peakall R, Smouse PE (2006) GENALEX 6: genetic analysis in Excel. Population genetic software for teaching and research. Mol. Ecol. Notes 6: 288-295

22. Nei M (1973) Analysis of gene diversity in subdivided populations. In: Proceedings of the National Academy of Sciences, USA. 70: 3321-3323

23. Perrier X, Jacquemoud-Collet JP (2006) Darwin software. http://darwin.cirad.fr/darwin.

24. Singh R, Sharma P, Varshney RK and Sharma SK (2008) Chickpea improvement: role of wild species and genetic markers. Biotechnol. Genet. Eng 25: 267-313

25. Maesen LJG (1972) Cicer L, A Monograph of the Genus, with Special Reference to the Chickpea (Cicer arietinum L.), Its Ecology and Distribution (Doctoral thesis) Wageningen University

26. Upadhyaya HD, R Oritz (2001) A mini core subset for capturing diversity and promoting utilization of chickpea genetic resources in crop improvement. Theor. Appl. Genet 102:1292-98

27. Mir RR, Varshney RK (2013) Future prospects of molecular markers in plants. In: R. J. Henry, Editor, Molecular markers in plants. Blackwell Publishing Ltd, Oxford, U.K. pp 170-190

28. Mir RR, Hiremath PJ, Riera-Lizarazu O, Varshney RK (2013) Evolving molecular marker technologies in plants: From RFLP to GBS. In: T.Lubberstedt and R. K. Varshney, Editors, Diagnostics in plant breeding. Springer, Dordrecht, The Netherlands pp 229-250.

29. Saxena MS, Bajaj D, Kujur A, Das S, Badoni S, Kumar V, et al (2014). Natural allelic diversity, genetic structure and linkage disequilibrium pattern in wild chickpea. PloS one 9(9): e107484

30. Upadhyaya HD, Dwivedi SL, Baum M, Varshney RK, Udupa SM, Gowda CLL (2008) Genetic structure, diversity, and allelic richness in composite collection and reference set in chickpea (Cicer arietinum L.). BMC Plant Biol 8: 106 
31. Imtiaz M, Materne M, Hobson K, Van Ginkel M, Malhotra RS (2008) Molecular genetic diversity and linked resistance to ascochyta blight in Australian chickpea breeding materials and their wild relatives. Aust. J. Agric. Res 59(6): 554-560

32. Castro P, Millan T, Gil J, Merida J, Garcia ML, Rubio J, Fernadez-Romero MD (2011) Identification of chickpea cultivars by microsatellite markers. J. Agric. Sci 149(4): 451-460

33. Khan R, Khan H, Harada F, Harada K. (2010) Evaluation of Microsatellite Markers to Discriminate Induced Mutation Lines, Hybrid Lines and Cultigens in Chickpea ('Cicer arietinum L.). Aust. J. Crop Sci 4(5): 301

34. Shukla N, Babbar A, Prakash V, Tripathi N, Saini N (2011) Molecular diversity analysis in some promising lines of chickpea using SSR markers. Journal of Food Legumes 24(4): 320-323

35. Samyuktha SM, Kannan JR, Geethanjali* S (2018) Molecular Genetic Diversity and Population Structure Analysis in Chickpea (Cicer arietinum L.) Germplasm using SSR Markers Int. J. Curr. Microbiol. Appl. Sci 7(2): 639-651

36. Mohan S, Kalaimagal T (2020). Genetic diversity studies in chickpea (Cicer arietinum L.) genotypes using SSR markers. Journal of Food Legumes 33(1): 1-5

37. Udupa SM, Sharma A, Sharma RP, Pai RA (1993) Narrow genetic variability in Cicer arietinum L. as revealed by RFLP analysis. J. Plant Biochem. Biotechnol 2(2): 83-86

38. Sonnante G, Marangi A, Venora G, Pignone D (1997) Using RAPD markers to investigate genetic variation in chickpea. J Genet Breed 51:303-307

39. Sant VJ, Patankar AG, Sarode ND (1999) Potential of DNA markers in detecting divergence and in analyzing heterosis in Indian elite chickpea cultivars. Theor Appl Genet 98:1217-1225

40. Singh R, Prasad CD, Singhal V, Randhawa GJ (2003) Assessment of genetic diversity in chickpea cultivars using RAPD, AFLP, and STMS markers. J Breed Genet 57: 165--174

41. Hajibarat Z, Saidi A, Hajibarat Z, Talebi R (2014) Genetic diversity and population structure analysis of landrace and improved chickpea (Cicer arietinum) genotypes using morphological and microsatellite markers. Environmental and Experimental Biology 12: 161-166

42. Saeed A, Hovsepyan H, Darvishzadeh R, Imtiaz M, Panguluri SK, Nazaryan R (2011) Genetic diversity of Iranian accessions, improved lines of chickpea (Cicer arietinum L.) and their wild relatives by using simple sequence repeats. Plant Mol. Biol. Rep 29(4): 848-858

43. Khamassi K, Bettaiëb Ben Kaab L, Khoufi S, Chaabane R, et al (2012) Morphological and molecular diversity of Tunisian chickpea. Eur. J. Hortic. Sci 77(1): 31

44. Bharadwaj CSK, Chouhan S, Satyavathi CT, Singh et al (2011) Molecular marker-based linkage map of chickpea (Cicer arietinum) developed from desi $\times$ kabuli cross. Int. J. Agric. Sci 81(2): 116-18

45. Sachdeva S, Bharadwaj C, Sharma V, Patil BS, Soren KR, Roorkiwal M, Varshney RK, Bhat KV(2018) Molecular and phenotypic diversity among chickpea (Cicer arietinum L.) genotypes as a function of drought tolerance. Crop Pasture Sci 69(2): 142-153 
46. Excoffier L, Smouse PE, Quattro J (1992) Analysis of molecular variance inferred from metric distances among DNA haplotypes: application to human mitochondrial DNA restriction data. Genetics 131(2): 479491

47. Roorkiwal M, Von Wettberg EJ, Upadhyaya HD, Warschefsky E, Rathore A, Varshney, RK (2014) Exploring germplasm diversity to understand the domestication process in Cicer spp. using SNP and DArT markers. PLoS One 9(7): e102016

48. Van Oss R, Abbo S, Eshed R, Sherman A, Coyne CJ et al (2015) Genetic relationship in Cicer sp. expose evidence for geneflow between the cultigen and its wild progenitor. PloS one 10(10): e0139789

49. Parween S, Nawaz K, Roy R, Pole A. K, Venkata S, Misra G, Jain M, et al (2015) An advanced draft genome assembly of a desi type chickpea (C. arietinum L.). Scientific Reports 5: 12806

50. Thudi M, Upadhyaya HD, Rathore A, Gaur PM et al (2014) Genetic dissection of drought and heat tolerance in chickpea through genome-wide and candidate gene-based association mapping approaches. PloS one 9(5): e96758

51. Gupta PK, Rustgi S, Mir RR (2008) Array-based high-throughput DNA markers for crop improvement. Heredity 101:5-18

52. PK Gupta, S Rustgi, RR Mir (2013) Array-based high-throughput DNA markers and genotyping platforms for cereal genetics and genomics. In: P.K Gupta and R.K Varshney (Eds.), Cereal Genomics II. Springer: The Netherlands

53. Kumar, S., Kumar, M., Mir, R. R., Kumar, R., Kumar, S. (2021) Advances in Molecular Markers and Their Use in Genetic Improvement of Wheat. In Wani SH, Mohan A and Singh GP (Eds.). Physiological, Molecular, and Genetic Perspectives of Wheat Improvement pp 139-174. https://doi. org/10.1007/978-3030-59577-7_8

54. Tyagi S, Kumar A, Gautam T, Pandey R, Rustgi S, Mir RR (2021) Development and use of miRNA-derived SSR markers for the study of genetic diversity, population structure, and characterization of genotypes for breeding heat tolerant wheat varieties. PLOS One 16(2):e0231063

55. Mir RR, Choudhary N, Bawa V, Jan S, Singh B, Bhat MA, Paliwal R, Gupta A, Chitikineni A, Thudi M, Varshney RK (2021) Allelic Diversity, Structural Analysis and Genome-wide Association Study (GWAS) for Yield and Related Traits using Unexplored Common bean (Phaseolus vulgaris L.) Germplasm from Western Himalayas. Frontiers in Genetics (Plant Genomics) DOI: 10.3389/fgene.2020.609603 


\section{Figures}

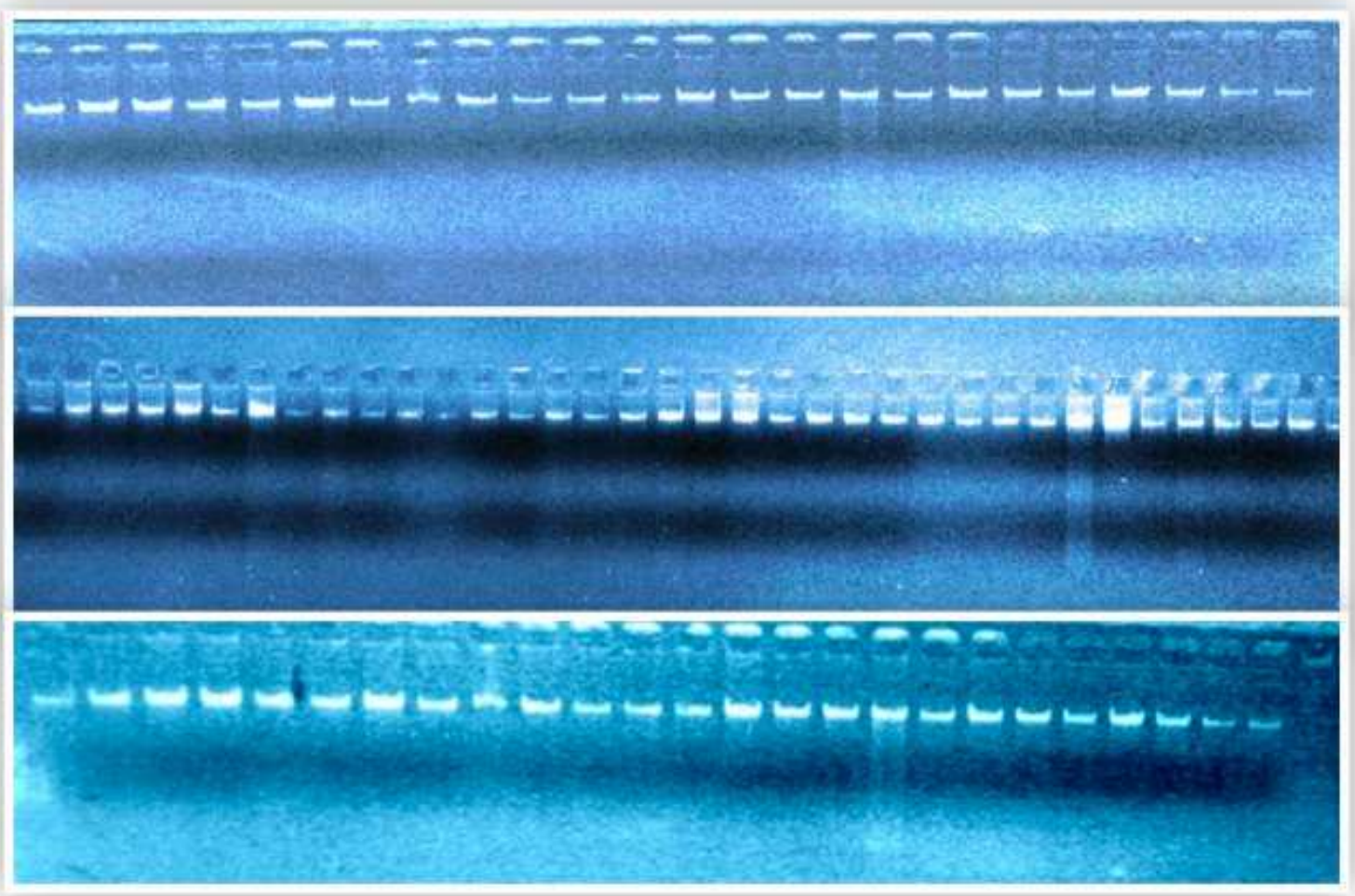

Fig. 1 Agarose gel image for quantification of DNA of core chickpea accessions

\section{Figure 1}

Please See image above for figure legend. 


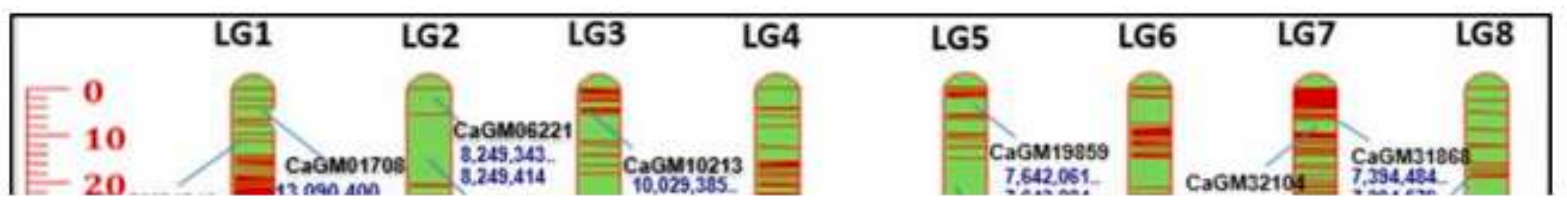

Figure 2

Please See image above for figure legend. 

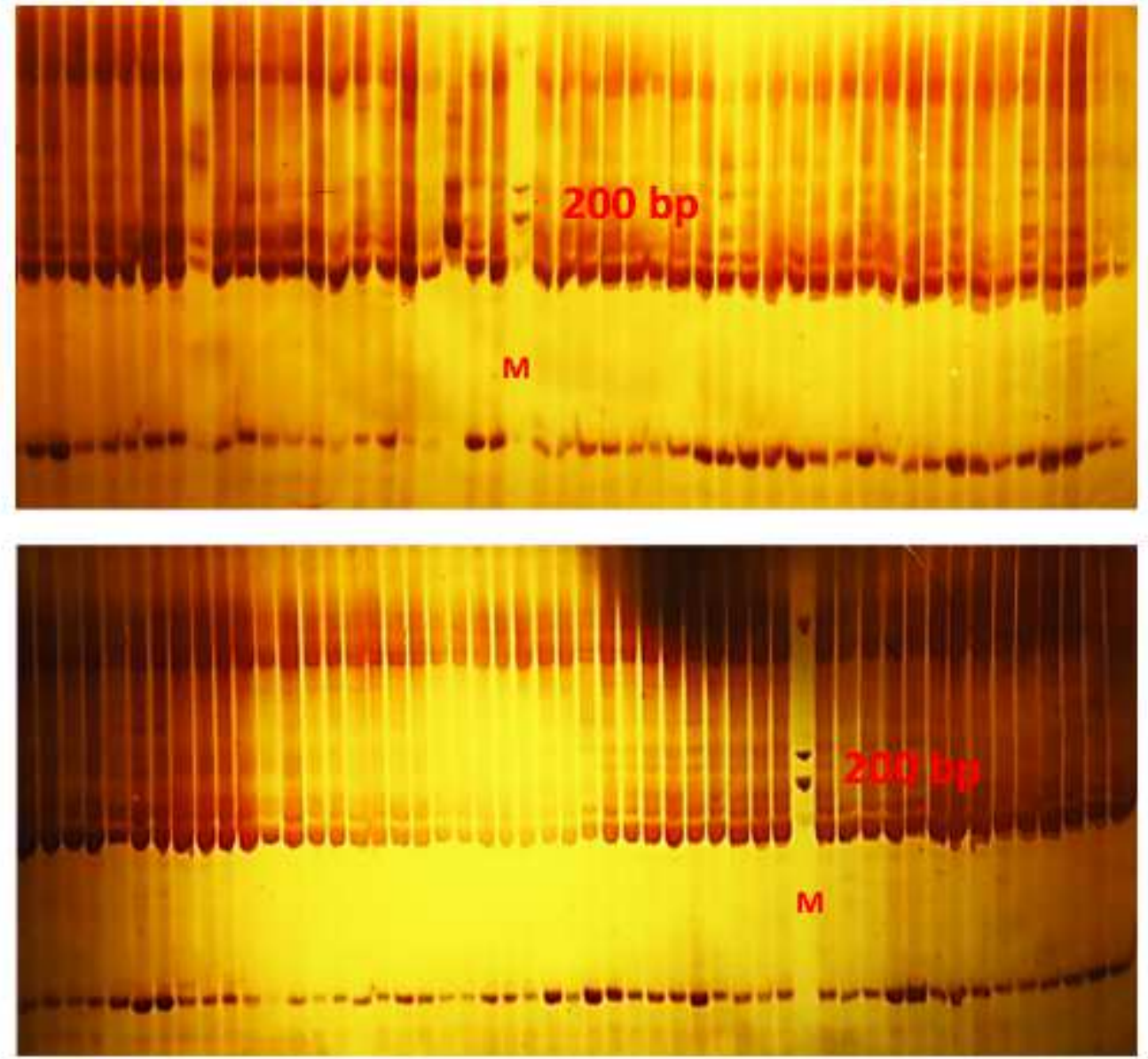

Fig. 3 SSR marker profile of chickpea germplasm generated by primer CaGM04755 (M = 100 bp ladder).

\section{Figure 3}

Please See image above for figure legend. 
Allelic Patterns across Populations
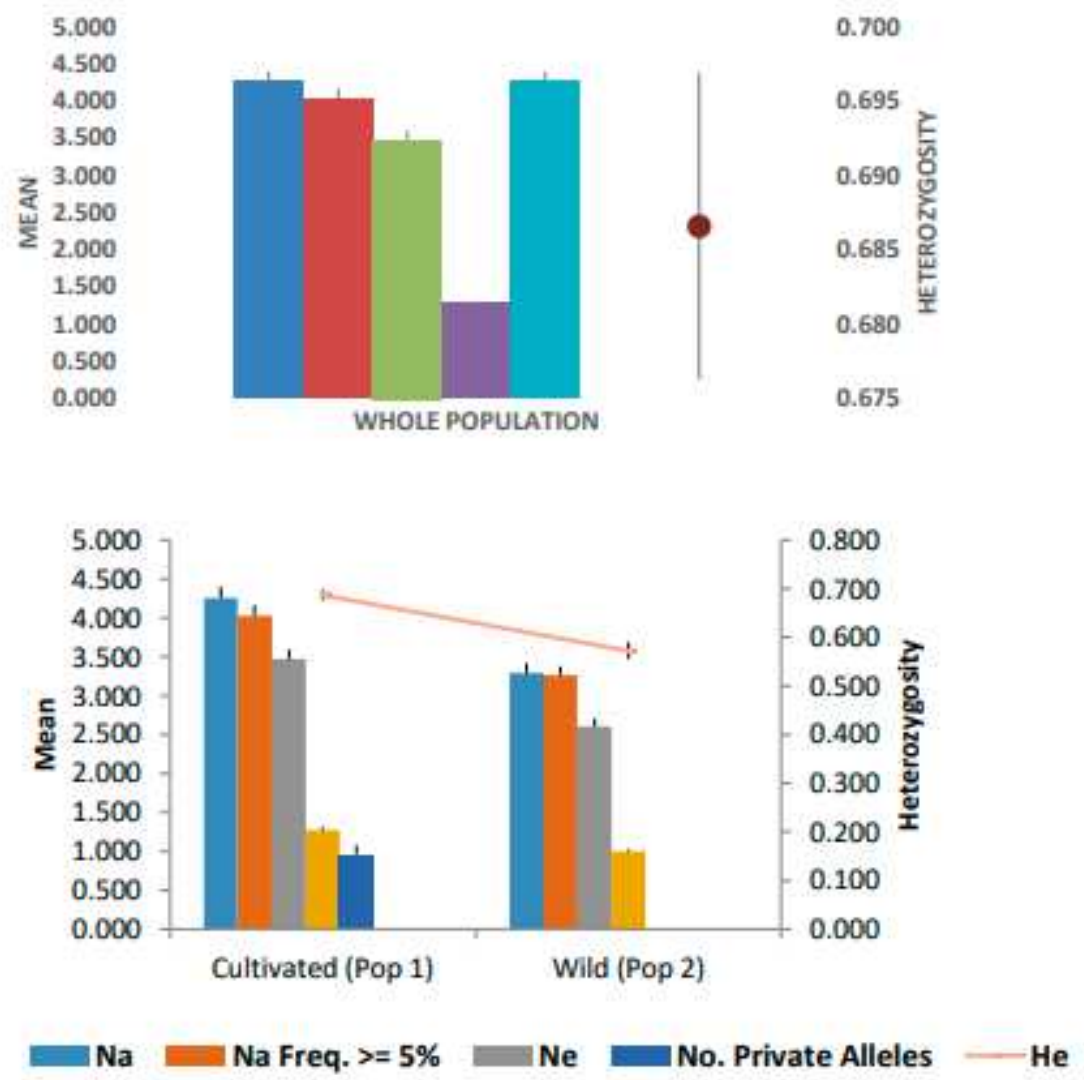

Fig. 4 Comparison of allelic and gene diversity detected in the whole chickpea population and two subpopulations (cultivated v/s wild).

\section{Figure 4}

Please See image above for figure legend. 


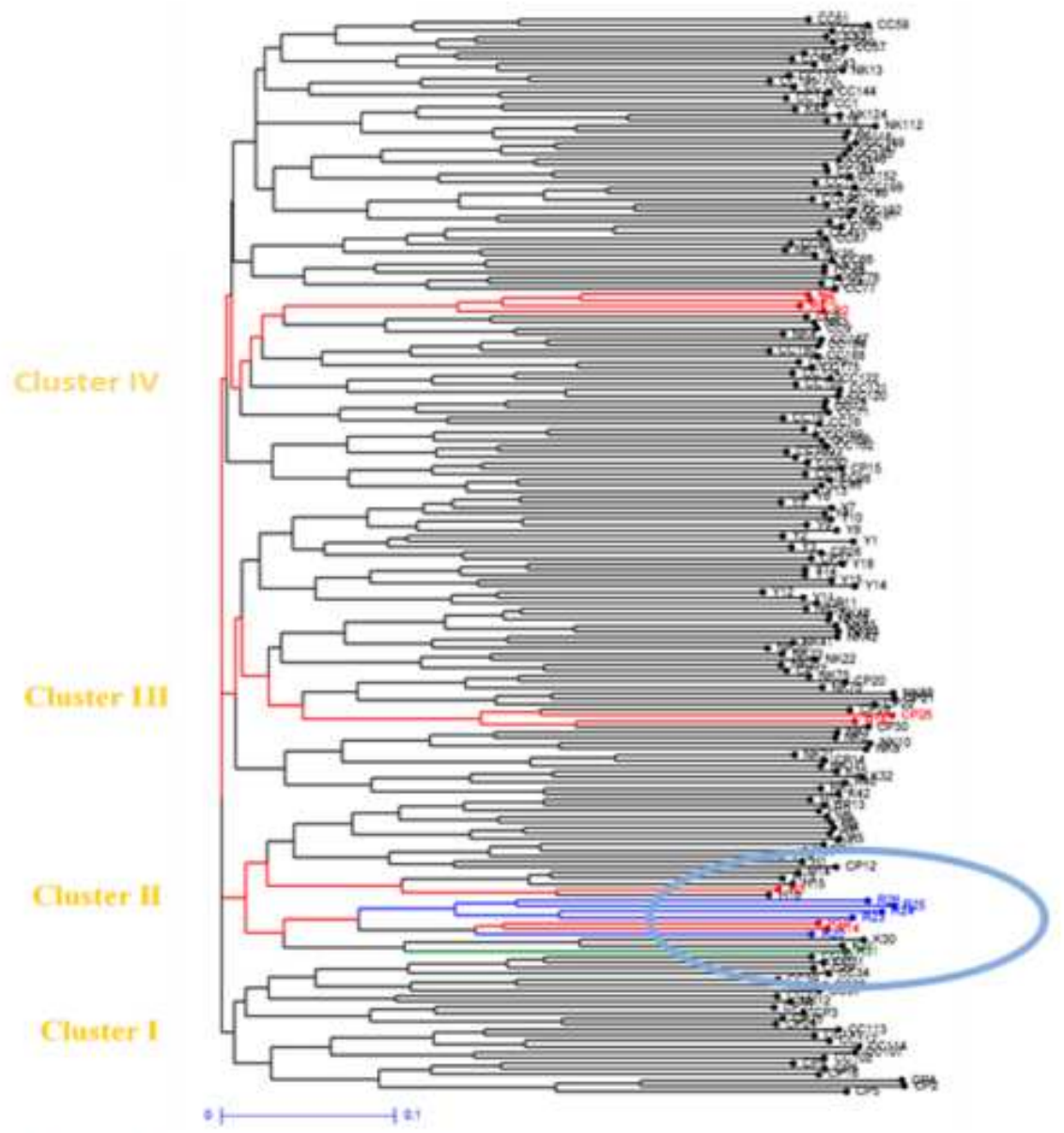

Fig. 5 Hierarchical clustering based on simple matching dissimilarity matrix genotyped across 192 core chickpea accessions using 33 SSR marker; Black lines indicate cultivated, Red ones are C. reticulatum, blue ones are C. echinospermum and green is C. microphyllum.

\section{Figure 5}

Please See image above for figure legend.

\section{Supplementary Files}

This is a list of supplementary files associated with this preprint. Click to download.

- SupplementaryTableEMS2.pdf 